\title{
Climatic water balance in Hamelmalo, Eritrea
}

\author{
Mehari Gebreyesus ${ }^{1}$ - Arzu Rivera Garcia ${ }^{1,2}$ - Géza Tuba ${ }^{2}$ - Györgyi Kovács ${ }^{2}$ - Lúcia Sinka ${ }^{1,2}$ - \\ József Zsembeli ${ }^{2}$ \\ ${ }^{1}$ Faculty of Agricultural and Food Sciences and Environmental Management, University of Debrecen, 4032 Debrecen, Böszörményi út 138. \\ Hungary \\ ${ }^{2}$ Karcag Research Institute, IAREF, University of Debrecen, 5300 Karcag, Kisújszállási út 166. Hungary \\ zsembeli@agr.unideb.hu
}

\section{SUMMARY}

\begin{abstract}
Agricultural production is an important sector for peoples to live, but it is highly affected by climate change. To have a good production we need to understand the climatic parameters which adversely affect production. Hamelmalo, which is located in the semi-arid area of Eritrea, is vulnerable to climate change and this is realised in the total production loss. Nevertheless, there is no concrete reference about the climate of the region due to lack of data for a long time. Changes in precipitation $(P)$, evapotranspiration $(E T)$ and, implicitly, in the climatic water balance (CWB), are imminent effects of climate change. However, changes in the CWB, as a response to changes in $P$ and ET, have not yet been analysed thoroughly enough in many parts of the world, including Eritrea. This study also explores the changes of the CWB in the Hamelmalo region, based on a wide range of climatic data $(P$, relative air humidity and evaporation pan necessary for computing potential evapotranspiration (PET) with the pan evaporation method) recorded at Hamelmalo from 2015-2019. This analysis shows that the annual cumulative CWB for Hamelmalo is negative in $67 \%$ of the years. The dry season without precipitation leads to negative CWB and the change in CWB only starts from the raining or crop season. Based on this recent study, 2015 had the highest PET and lowest $P$, and this resulted in the lowest CWB in the investigated period. Opposite to this, 2019 had lower PET and highest $P$, which led to the highest CWB. However, the monthly values of CWB did not correlate with the annual $P$ or ET. On the base of our study, it can be concluded that PET and P were very variable in the investigated years and $P$ was the most influential elements of $C W B$.
\end{abstract}

Keywords: climate change; water balance; precipitation; potential evapotranspiration

\section{INTRODUCTION}

Climate change guides to a rise in the frequency and intensity of weather extremes, particularly droughts, heavy precipitation and storms (Hasson et al., 2016) which are highly disastrous to the environment. In a hot region, the whole earth's water cycle adjusts as a consequence of the entire rise in precipitation and evapotranspiration. Nevertheless, the changes are different at different regions like in some global areas, the humidity increased while others are becoming progressively dry (IPCC, 2013). In tropics, greater content of water in the atmosphere impacts rainfall amount (IPCC, 2007) and the net change of water cycle builds up on evapotranspiration dynamics.

Climate change and its influence on crops may be the main concern for many researchers and policy makers (Kang et al., 2014) and its negative consequence has already been accomplished by many food producers in the world (Ndawayo, et al., 2017). Global warming is particularly alarming since the $20^{\text {th }}$ century (IPCC, 2013) and it is the most motivation of several environmental changes, including precipitation (P) and evapotranspiration (ET) changes, which are the principal climatic parameters for any crop growth, and changing of these two climatic variables also leads to a change in climatic water balance (CWB). Climate change influence in water resource is especially common in regions with limited amount of water for economic development (Cudennec et al., 2007) and the involvement of climate changes on agriculture dependent livelihood and hydrological systems are outstanding at regional extent (Bastakoti et al., 2014).
At the same time climate change also impacts the overall CWB for different countries.

CWB is the difference of $\mathrm{P}(\mathrm{mm})$ and potential evapotranspiration (PET, $\mathrm{mm}$ ) determined for a defined period of time (Equation 1).

$$
\mathrm{CWB}=\mathrm{P}-\mathrm{PET}
$$

The calculation of CWB was not common, but in the recent decades, notable changes in CWB were reported across the globe. Though it is hard to conduct a common analysis, to a certain extent, owing the fact that ET trend is not a must to be positive in a warmer climate due to several factors like low wind speed and decreased solar radiation. Modern climate models propose that remarkable possible future rise in global precipitation and evapotranspiration will highly show the climatic water shortage in large regions (Feng and $\mathrm{Fu}, 2013)$. Given these cases, an amplification of arid environments is probably to exist in some parts of the world including Saharan regions and southern Africa, where Eritrea is part of it. There has been a prediction that by 2100 , dry lands will cover approximately $56 \%$ of the world's land area under representative concentration pathway RCP8.5 (Huang et al., 2016). That is opposite to the most recent assessment of $45 \%$ and the commonly acceptable statement that says dry gets drier and wet gets wetter must be reworded by dry gets drier but too wet gets wetter (Prăvălie, 2016). In fact, application of the CWB advances our capacity to predict the consequence of climatic changes on the biological world.

Eritrea is highly vulnerable to climate change (UNFCCC, 2001), and water is the most limiting factor 
for crop growth as part of the sub-Saharan Africa (Lal, 1991). Agriculture is the top priority for economic development in the whole country with $80 \%$ of the population depending on agricultural farming and livestock (IPCC, 2007). Agriculture is the sector highly influenced by climate variability with important involvements for agricultural efficiency and food security, mainly in the developing world (FAO, 2017) where Eritrea belongs. Hamelmalo, a sub-region in Eritrea, is also afflicted with all the above-mentioned problems. People depend on rain-fed agriculture for their living, especially sorghum is the top crop followed by pearl millet and this is characteristic all over the country (UNFCCC, 2001). Yield is highly low for instance; average yield of sorghum in Hamelmalo is $0.2-0.6 \mathrm{t} \mathrm{ha}^{-1}$ in a good rainfall period (MOA, 2005). This may be due to several factors, but one of them is climate variability that can cause variation in precipitation and evapotranspiration or CWB. In fact, there is no scientific study and evidence; however several human and natural activities are already exposed to CWB changes in the world. Therefore, to have good crop production, studying all climatic variables in general and particularly CWB is of paramount importance. Additionally, in dry and semidry regions or areas with shortage of water like Eritrea, irrigation consumes a lot a water (Singh et al., 2017). Hence, precise appraisal of crop water requirement for better and efficient irrigation scheduling (Gong et al., 2019) is highly significant. This study includes the estimation of CWB that can aid to determine accurate water requirements to reduce water loss and increase water use efficiency.

As the preconception of our research work, we assumed that climate is a real issue and can be quantified locally by means of the analysis of measured meteorological data. According to this preconception, our hypothesis was that the tendency of local climate change can be figured out proving the existence of climate change. Furthermore, these data, especially CWB, are suitable for the assessment of local climate and for the establishment of practical conclusions and recommendations regarding the accommodation to the changing climatic conditions from agrotechnical point of view. The general objective of this study is to assess annually and seasonal (sorghum growing season) CWB on the base of the meteorological data recorded at the meteorological station of Hamelmalo for the period of 2015-2019. The specific aim is to analyse CWB variability, determine its extremes and the difference between the investigated years.

\section{MATERIALS AND METHODS}

Eritrea is located between latitudes $12^{\circ} 40^{\prime}-18^{\circ} 02^{\prime}$ $\mathrm{N}$ and longitudes $36^{\circ} 30^{\prime}-43^{\circ} 20^{\prime} \mathrm{E}$ in the east of Africa and southern border of sub-Saharan Africa. Eritrea is considered as one of the highly exposed countries to a change of climate owing to geographical location with limited level of knowledge with shortage of data and interpretation (UNFCCC, 2001). The impacts of climate change are clearly shown on the environment like land degradation, desertification, agriculture worsen food insecurity, loss of biodiversity and elongated drought are common in the country. The elongated drought has a great impact on water resource especially drinking water and this leads to water scarce in the country (Eritrea, 2004).

Precipitation is the most variable climatic parameter with erratic, torrential features and great variation of short duration and high intensity from year to year. There are two rain seasons in the whole country, with June-September (extends from highlands to western region of the country) and October-March (covers eastern escarpments) and also there are short precipitations in April and May along with highest precipitation records in July and August (FAO, 1994). Mean annual rainfall ranges from less than $200 \mathrm{~mm}$ (in the semi-desert) to $1100 \mathrm{~mm}$ (in the sub-humid zone) (UNFCCC, 2001) and in most part of Eritrea, southwestern monsoon winds are the main source of precipitation during summer and spring seasons (FAO, 1994). The mean annual temperature varies from $18^{\circ} \mathrm{C}$ (in the moist and arid highlands) to $32{ }^{\circ} \mathrm{C}$ (in the semidesert) (FAO, 2005).

\section{The study area}

The study is related to Hamelmalo (Eritrea) located on $15^{\circ} 52^{\prime} 16^{\prime \prime} \mathrm{N}$ and $38^{\circ} 27^{\prime} 44^{\prime \prime} \mathrm{E}$ latitude and longitude, respectively. Its elevation is $1,278 \mathrm{~m}$ and it has semiarid climate. In Hamelmalo, $80 \%$ of the population depends on agricultural farming and livestock, which are highly sensitive to the disturbances in the climate system (IPCC, 2007). The most common crops grown in Hamelmalo in order of their importance are sorghum, pearl millet, barley, maize, peanut, wheat, and finger millet. Rainfall is short duration, torrential and varying from year to year. So far, there is no much data about average precipitation and mean temperature. Agriculture is mainly rain-fed and exposed to climatic variability. Although precipitation seems to be sufficient for resistant crops, especially for sorghum, but low yields are characteristic owing to serious shortage of water during the flowering or seeding period (September-October), hence additional irrigation is highly needed to increase yield (Ramesh and Ogbazghi, 2010). Low agricultural productivity and land degradation have become the major features of this sub-region.

Most part of the land in this region is not cultivated due to steep slopes (Ramesh and Woldeselassie, 2010). Soils in Hamelmalo are dominantly light or medium light. Generally, they are loamy sand and sand soils with dominant sand and some percentage of silt, clay, cobbles and boulders forming a porous bed, some organic matter and average bulk density of soil surface ranged from $1.54 \mathrm{Mg} \mathrm{m}^{-3}$ to $1.69 \mathrm{Mg} \mathrm{m}^{-3}$ (Ramesh et al., 2015).

In the study area, there is an agricultural college (Hamelmalo Agricultural College) where research activity is ongoing. Nevertheless, there is a shortage of climate data due to lack of meteorological stations in the region making meteorological analyses difficult. Generally, for long time climate related studies was not 
common in Eritrea. It was at regional level along with the countries of Greater Horn of Africa (Camberlin and Philippon, 2002). The first meteorological station of Hamelmalo has been working since 2009, but it was only measuring the amount of rainfall. However, in 2015, a new, complete meteorological station was established according to the standards, i.e. the climatic parameters needed for this study have been available since 2015. This study can help researchers to have general understanding about the climate or weather of the region as a basic reference.

\section{Climatic water balance computation}

CWB (mm) values were computed based on the difference between precipitation and potential evapotranspiration according to the following formula: P-PET $=$ CWB . The result can be explained as a water deficit if PET is lower than P, while water surplus occurs in a vice-versa case. Climatic water deficit is the potential of reduced water and leads to plant stress if it continues for a long time but we should not confuse it with soil water deficit. However, climatic water surplus is the potentially available water that can be used by the plant for biological process and the excess can be runoff, evaporated or transpired (Nathan, 2011). As Kerkhoff et al. (2004) reported, plant ecologists use CWB to analyse the hydrological conditions of a certain region. Another report from California indicates that a change in species dispersal to a change in CWB is more significant than a shift in temperature
(Crimmins et al., 2011). Actually, soil water balance is a more useful estimator physiologically, however its computation asks more details and it is not an easy to compute by the plant ecologists (Piedallu et al., 2013).

In this study, CWB was calculated on a daily basis. Annual cumulative values and the cumulative values for each crop growing month of sorghum were computed and illustrated. The crop growing season of sorghum was determined as the period of July-October. (The raining season, in general, lasts from June to September). In this study, the average of the five years in each figure was used as a basis to compare the differences. Person's chi-squared test was used for the statistical analysis in order to determine whether there was a statistically significant difference between the average and the values of the investigated years.

\section{RESULTS AND DISCUSSION}

The annual values of PET and $\mathrm{P}$ as the factors determining CWB for the investigated period are shown in Figure 1. There was a linear decrease in annual PET during the investigated period in the range from approximately 1,800 down to $1,500 \mathrm{~mm}$. This decrease was related to the decrease in temperature and in some cases with increase in humidity but in a small magnitude. Precipitation was randomly distributed, in some years higher in other years lower varying in the range of 200-600 mm, approximately.

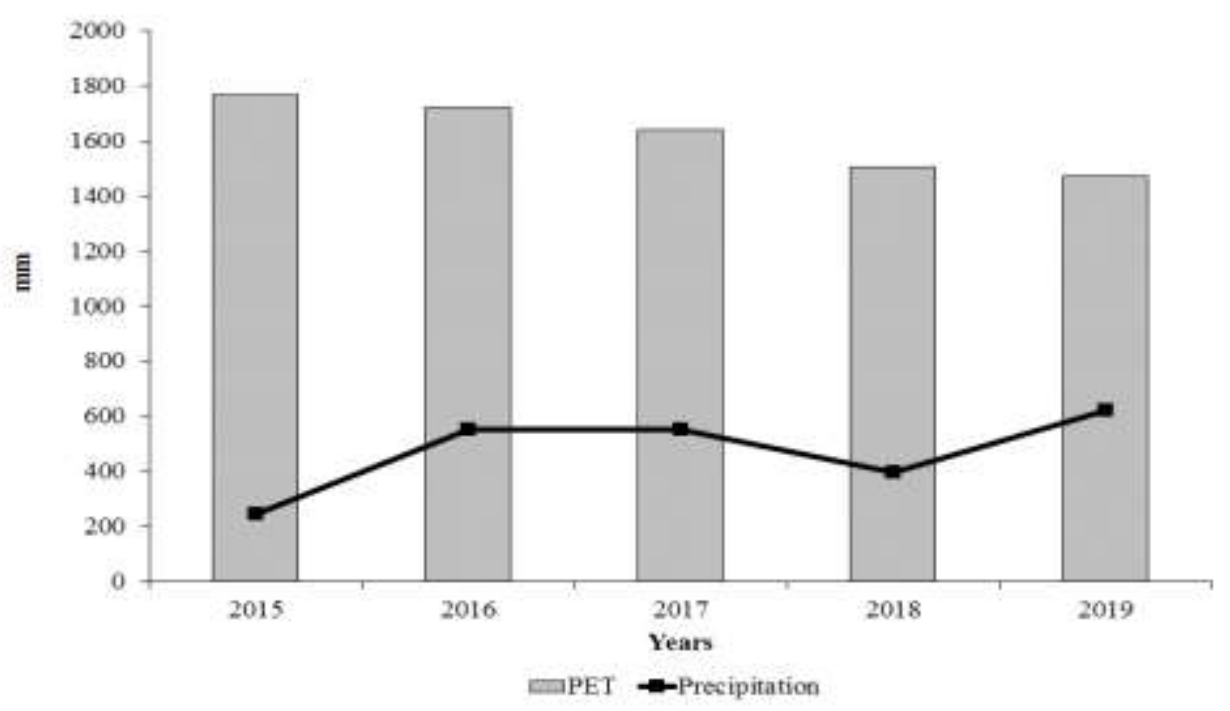

The monthly values of PET and $\mathrm{P}$ recorded in Hamelmalo for the investigated period are shown in Figure 2. In general, the mean monthly PET and P of the five years indicate positive CWB from July until September ensuring potentially available water for crop production. In case of rainfed farming, crop production must be adjusted within this time. Most of the time, short growing season crops are advantageous in this region, otherwise additional water is needed. The effective period, which encourages good CWB to have a good yield, is from around $20^{\text {th }}$ of June until $15^{\text {th }}$ of September.

The annual cumulative values of CWBs calculated for Hamelmalo for the investigated years are shown in Figure 3. Based on the chi-squared test for the annual cumulative CWB, no significant difference was found 
for the years of 2016, 2017 and 2018, respectively, but there was a significant difference from the average CWB in the years of 2015 and 2019. Generally, annual cumulative CWB of 2017, 2018 and 2019 were above the average and the remaining years were below. Year 2015 had the lowest annual cumulative CWB (-1534.8 $\mathrm{mm})$ and 2019 had the highest $(-852 \mathrm{~mm})$.

Figure 2. Mean monthly precipitation and potential evapotranspiration in Hamelmalo (2015-2019)

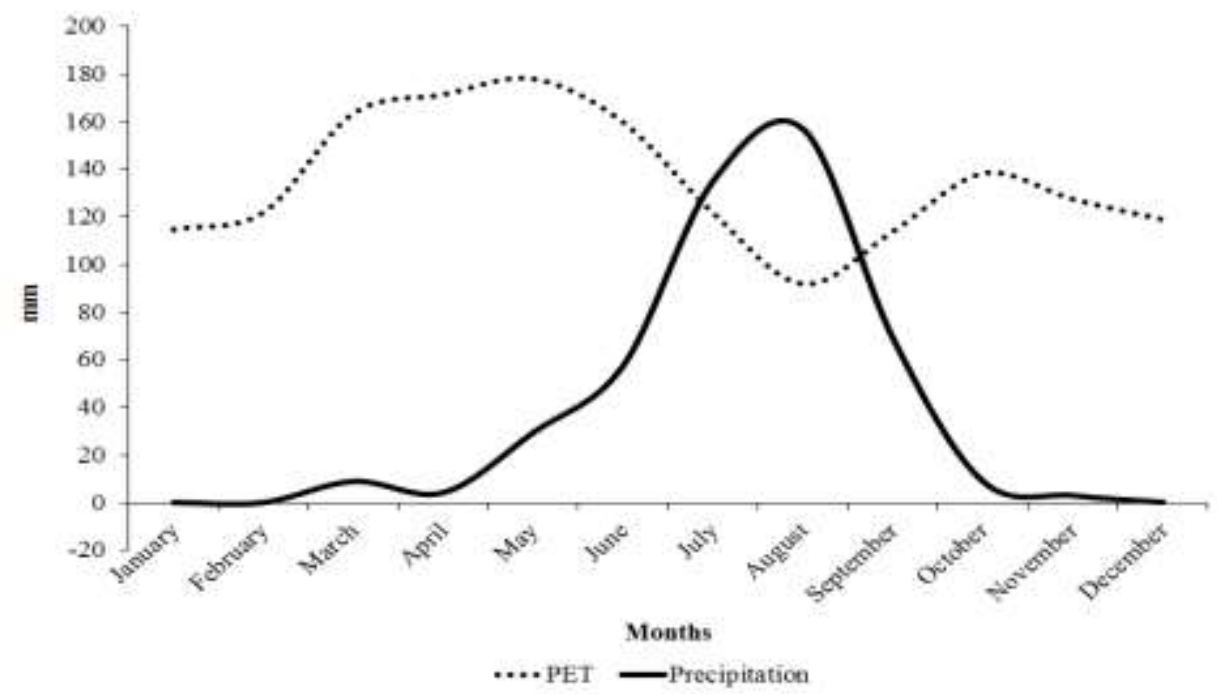

Figure 3. Annual cumulative climatic water balance (CWB) in Hamelmalo (2015-2019)

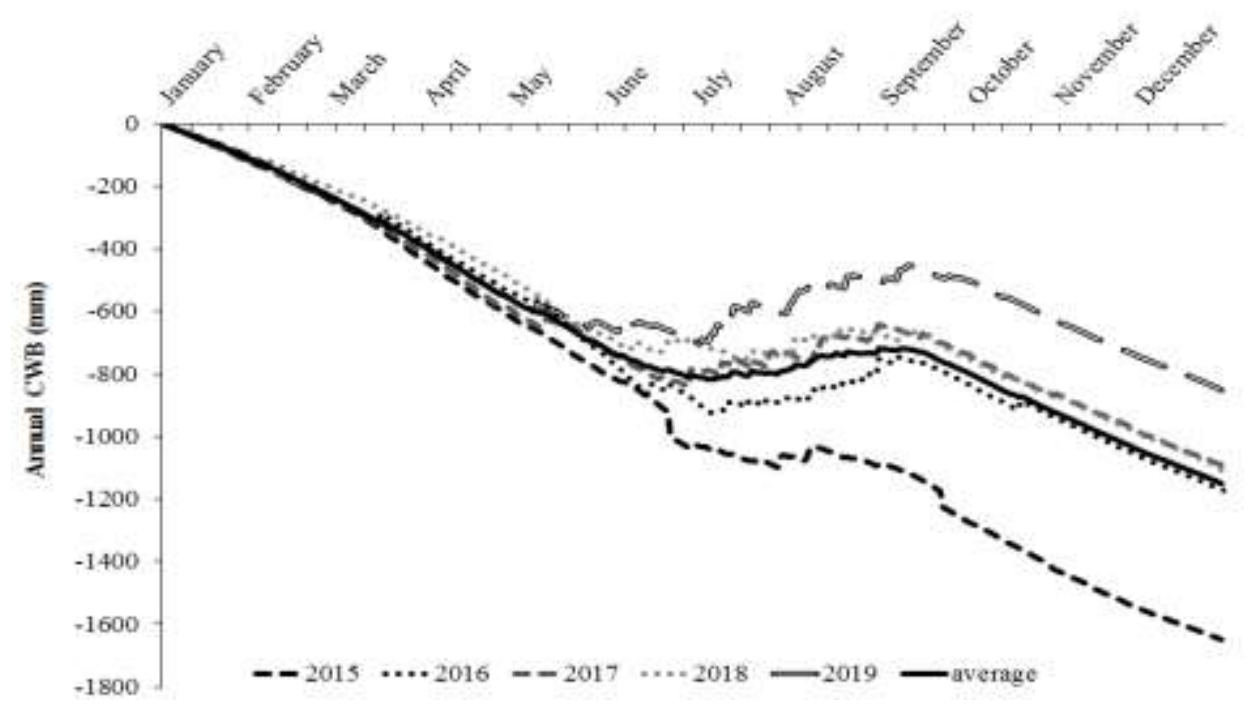

Based on the result of the chi-squared test, the cumulative CWBs of the crop growing seasons (JulyOctober) showed a significant difference in all the years under study except 2016. The cumulative seasonal CWBs of 2017 and 2019 were above the average, while the remaining years were below. Year 2015 had the lowest cumulative seasonal CWB $(-317.6 \mathrm{~mm})$ and 2019 had the highest $(79.2 \mathrm{~mm})$. Most of the time, crop planting is started from the end of June and beginning of July because the farmers do not start sowing immediately after rain starts. They plough the land two times before sowing and the duration of rain is too short which leads to low production due to the shortage of water during the flowering stage. In the vegetation period of sorghum, the main influential factor for the significant differences in seasonal CWB was precipitation.

In Figure 4 the cumulative CWBs of July are shown for the investigated years. Based on the chi-square test, there was a significant difference from the average 
CWB in all years (no exception). The cumulative CWBs of 2017 and 2019 were positive and above average while the remaining years were negative and below average (the average is slightly positive). Year $2015 \mathrm{had}$ the lowest cumulative CWB $(-64.6 \mathrm{~mm})$ and 2016 had the highest $(106.6 \mathrm{~mm})$.

July is the month with the second highest $\mathrm{P}$ after August when most crops are sown. In this month, there was a remarkable variation in the values of cumulative $\mathrm{CWB}$ in all years due to the greatest variation in precipitation. The negative values for cumulative CWB indicates water deficit calculated for 2015, 2016 and 2018, respectively. In the other two years (2017 and 2019) water surplus was characteristic owing to high amounts of P comparatively. For 2015 and 2018, the main cause was lower P, but negative CWB in 2016 was due to the high evaporation rate related to high temperature even $\mathrm{P}$ was also high.

The cumulative CWBs of August are illustrated in Figure 5. The chi-squared test showed that there was a significant difference from the average CWB in the years of 2015 and 2019, but there was no significant difference in the years of 2016, 2017 and 2018, respectively. Generally, the cumulative CWB for all years were positive except in 2017 at the beginning few days of the month. Year 2015 had the lowest $(16.9 \mathrm{~mm})$ and 2019 had the highest $(111.8 \mathrm{~mm})$ values of cumulative CWB.

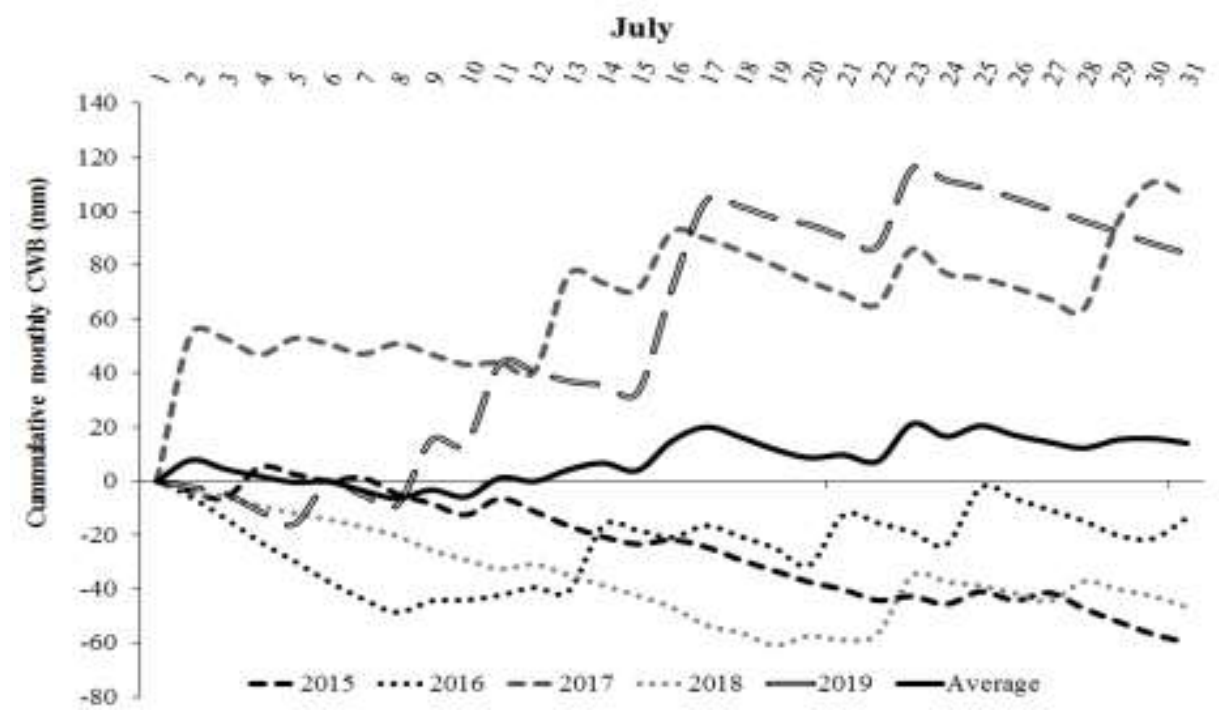

Figure 5. Monthly cumulative climatic water balance in August in Hamelmalo (2015-2019)

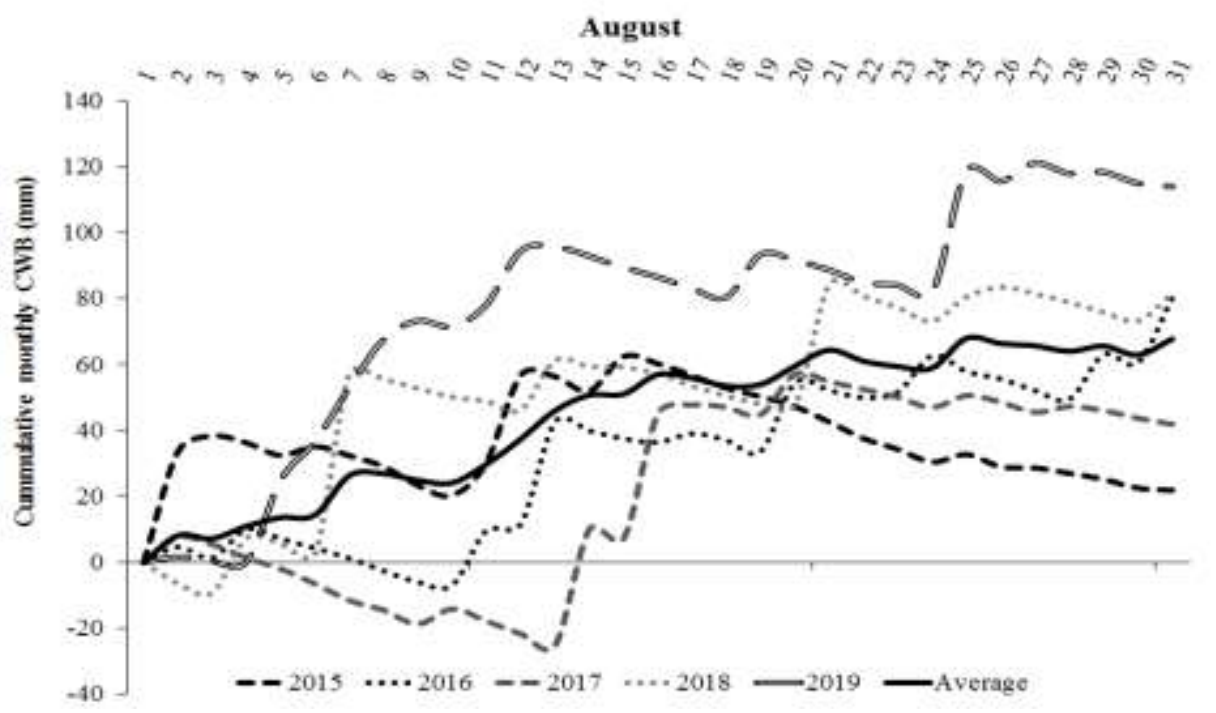

In Figure 6, the cumulative CWBs of September are introduced. The chi-squared test showed significant difference from the average CWB in the years of 2015 (much below), 2016 (above), and 2019 (above), respectively. No significant difference was figured out for the years of 2017 and 2018. 2015 had the lowest 
$(-122.4 \mathrm{~mm})$ and 2019 had the highest $(1.8 \mathrm{~mm})$ cumulative CWB value.

In September, $\mathrm{P}$ generally decreased slowly and CWB also decreased and became negative. The variation in $\mathrm{CWB}$ was due to the difference in precipitation from year to year in that month. In 2015 , there was less amount of precipitation than in other years leading to a low, evenly decreasing CWB and less water supply for crops. The CWB calculated for such periods is a good indicator of the demand of irrigation. In 2018 and 2019, P arrived late, its amount was enough to generate a positive CWB in 2019, but not in 2018. In 2016 and 2017, the early and sufficient amount of $\mathrm{P}$ resulted in positive CWB getting to be negative only at end of the month.

The cumulative CWBs of October are illustrated in Figure 7. No remarkable differences from the average cumulative CWB could be figured out in any of the investigated years by means of the statistical analysis. Year 2015 had the lowest $(-152.2 \mathrm{~mm})$ and $2016 \mathrm{had}$ the highest $(-111.6 \mathrm{~mm})$ values of cumulative CWB. 2019 was found to be an average year in this respect.

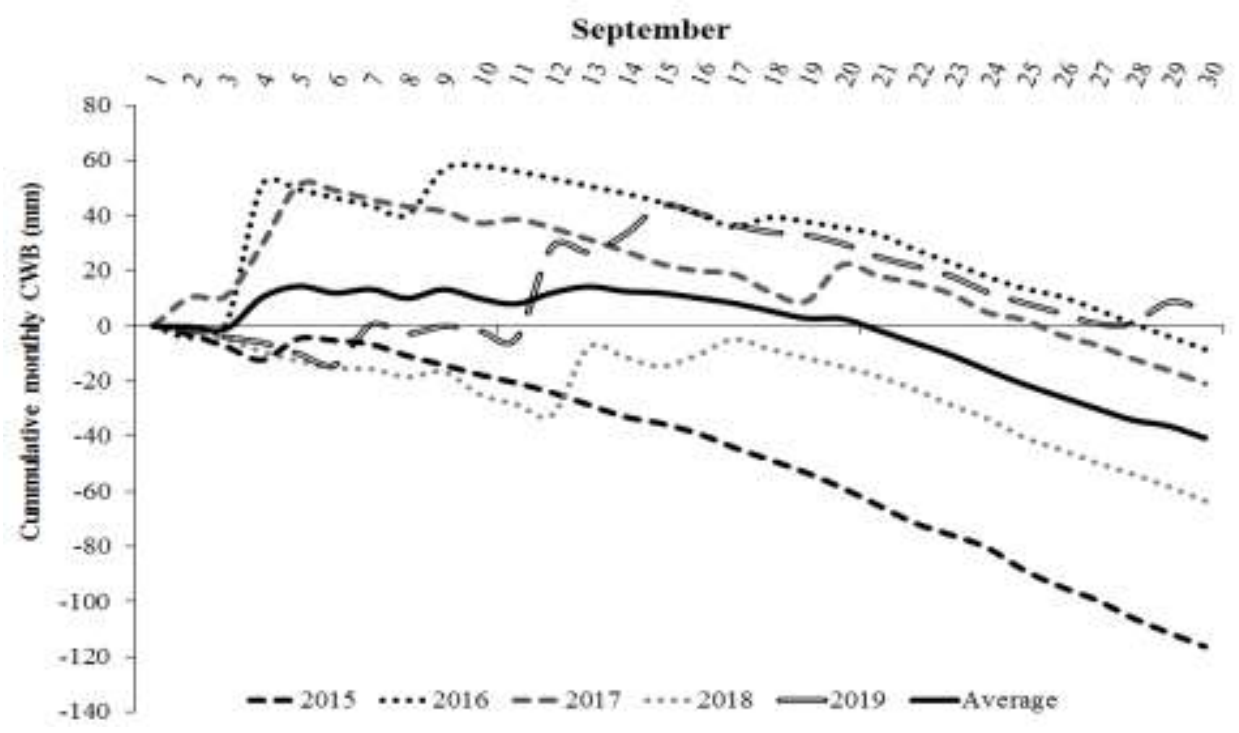

Figure 7. Monthly cumulative climatic water balance in October in Hamelmalo (2015-2019)

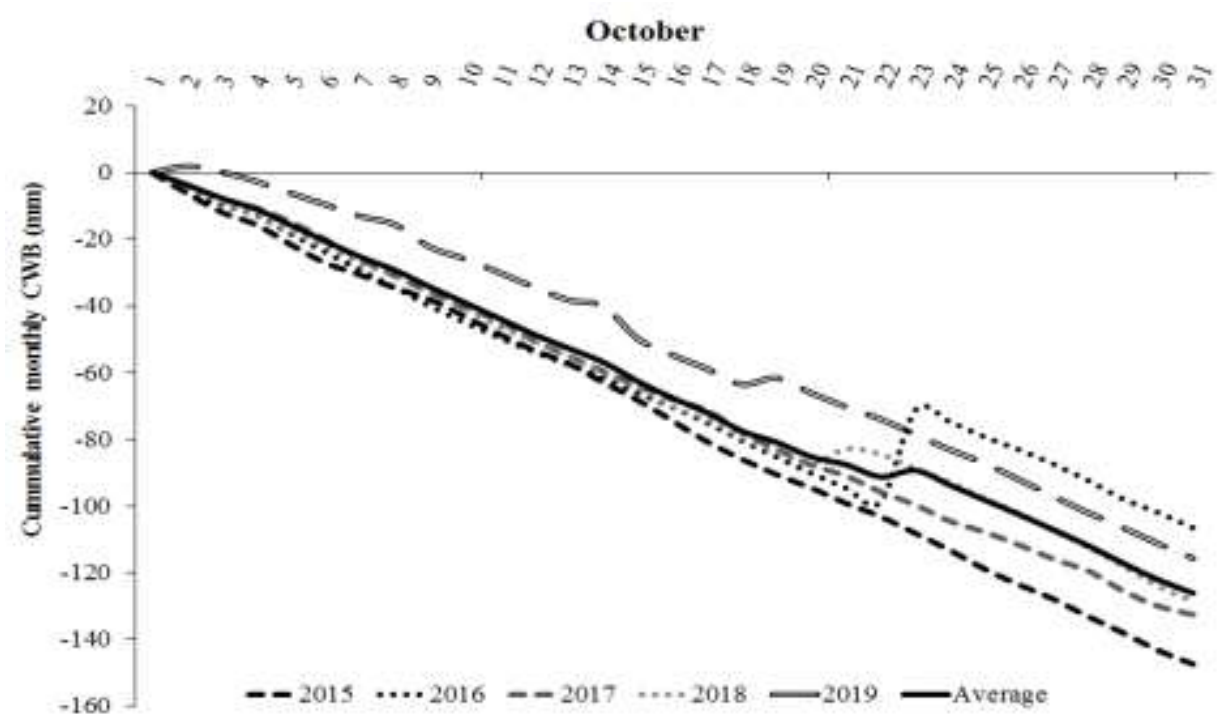

Typically, there is no $\mathrm{P}$ in October in Hamelmalo, except for some seldom cases. The lack of $\mathrm{P}$ resulted in negative cumulative $\mathrm{CWB}$ and no convincing variation in CWB was found among the investigated years. Nevertheless, 2016 was a unique year as there was a sudden change in CWB in the last third of the month 
due to $30.5 \mathrm{~mm}$ unusual rainfall. The most influential factor was $P$ in this month, which is not supportive for crop production due to the lack of rainfalls. In October, sorghum crops require additional water supply to have good yields in Hamelmalo.

\section{CONCLUSIONS}

In this study, we analysed some meteorological data recorded in Hamelmalo, Eritrea in order to quantify some fractions of climate change. CWB for five consecutive years were calculated and compared to their average in order to assess the variation of this parameter. The two main factors ( $\mathrm{P}$ and PET) determining CWB were also analysed. Annual PET decreased linearly during the investigated years, 2015 had the highest, 2019 had the lowest value, Annual P showed the same variation and trend. Logically, annual CWB was the lowest in 2015, while the highest in 2019. Even both of these variables require attention in the assessment of annual CWB, we found $\mathrm{P}$ to be the most influential factor in this respect. The annual CWBs were negative due to the fact that in approximately $67 \%$ of a year is dry without precipitation. Nevertheless, the analysis of the CWB for the vegetation period of sorghum showed that positive CWB is characteristic, hence sufficient water supply, to the months when sorghum has the highest water demand. Naturally, the considerable variations make irrigation plans and crop production less predictable. On the base of our results, we can conclude that $\mathrm{P}$ was the most determining factor in the variation of CWB in Hamelmalo, Eritrea during the investigated five years of the study. In general, high $\mathrm{P}$ was related to high CWB and low $\mathrm{P}$ to low CWB. However, temperature also plays an important role in correlation with PET. Regarding other climatic parameters, we could not figure out a significant effect on CWB, except for some months when humidity had a small impact. Based on the result of five years, we figured out an increasing trend in $\mathrm{P}$ assuming no decrease in CWB in Hamelmalo in the near future. However, longer-term research of the meteorological data is required for more precise and reliable predictions. Evaluation of the climatic parameters is important for estimating climate change. Consideration of CWB improves our ability to understand and forecast the effects of climatic change and aids agricultural practice, especially in terms of the application of proper irrigation.

\section{REFERENCES}

Bastakoti, R.C.-Gupta, J.-Babel, M.S.-van Dijk, M.P. (2014): Climate risks and adaptation strategies in the Lower Mekong River basin. Reg. Environ. Chang. 14 (1), 207-219.

Camberlin, P.-Philippon, N. (2002): The East African March-May rainy season: associated atmospheric dynamics and predictability over the 1968-97 period. Journal of Climate, 15(9), 1002-1019.

Crimminis, S.M.-Dobrowski, S.Z.-Greenberg, J.A.-Abatzogla, J.T.-Mynsberge, A.R. (2011): Changes in climatic water balance drive downhill shifts in plant species optimum elevations Science, 331, 324-327.

Cudennec, C.-Leduc, C.-Koutsoyiannis, D. (2007): Dryland hydrology in Mediterranean regions-a review. Hydrol. Sci. J. 52, 1077-1087.

Eritrea (2004): Interim Poverty Reduction Strategy Paper. Asmara.

FAO (1994): Agricultural Sector Review and Project Identification. Food and Agricultural Organization of the United Nations, Rome.

FAO (2005): Irrigation in Africain figures - AQUASTAT Survey, http://www.fao.org/nr/water/aquastat/countries_regions/ERI/ER I-CP_eng.pdf.

FAO (2017): Migration, Agriculture and Climate Change. Reducing Vulnerabilities and Enhancing Resilience. United Nations Rome Technical report.

Feng, S.-Fu, Q. (2013): Expansion of global drylands under a warming climate. Atmos. Chem. Phys. 13, 10081-10094.

Gong, X.-Liu, H.-Sun, J.-Gao, Y.-Zhang, H. (2019): Comparison of Shuttle worth-Wallace model and dual crop coefficient method for estimating evapotranspiration of tomato cultivated in a solar greenhouse. Agric. Water Manag. 217, 141-153.

Hasson, S.-Pascale, S.-Lucarini V.-Böhner, J. (2016): Seasonal cycle of precipitation over major river basins in South and Southeast Asia: a review of CMIP5 climate models data for present climate and future climate projections. Atmos Res 180:42-63.

Huang, J.-Yu, H.-Guan, X.-Wang, G.-Guo, R. (2016): Accelerated dryland expansion under climate change. Nat. Clim. Chang. 6, 166-172.

IPCC (2007): The physical science basis. In Contribution of Working Group I to the Fourth Assessment Report of the Intergovernmental Panel on Climate Change. In: Solomon, S.Qin, D.-Manning, M.-Chen, Z.-Marquis, M.-Averyt, K.B.Tignor, M. and Miller, H.L. (Eds.) Cambridge and New York, NY: Cambridge University Press.

IPCC (2013): Climate change: the physical science basis. In: Stocker, T.F. (Ed.), Contribution of Working Group I to the Fifth Assessment Report of the Intergovernmental Panel on Climate Change. Cambridge University Press, Cambridge.

Kang, Y.-Ma, X.-Khan, S. (2014): Predicting climate change impacts on maize crop pro ductivity and water use efficiency in the loess plateau. Irrig. Drain. 63, 394-404.

Kerkhoff, A.J.-Martens, S.N.-Shores, G.A.-Milne, B.T. (2004): contingent effects of water balance variation on tree cover density in semi-arid and Biogeography, 13, 237-246.

Lal, R. (1991): Current research on crop water balance and implications for the future: In: Proceedings on soil water balance in the Sudano- Sahelian zone, Niamey, pp. 31-43.

MOA (2005): Ministry of agriculture. Area and Production by Zoba from 1992-2005. Eritrea.

Nathan, L.-Stephenson (AGU, 2011.ppt). The climatic water balance in an ecological context. USGS science for a changing world Western Mountain Initiative.

Ndawayo, B.A.-Shamsudin, M.N.B.-Radam, A.B.-Abdullah, A.M.B. (2017): Impact of climate change on maize yield in the maize growing region of Nigeria. Int. Res. J. Environ. Sci. 6, 2024. 
Piedallu, C.-Gégout, J.-Perez, V.-Lebourgeois, F. (2013): Soil water balance performs better than climatic water variables in tree species distribution modeling Global Ecology and Biogeography, Wiley, 22, pp.470-482.

Prăvălie, R. (2016): Drylands extent and environmental issues. A global approach. Earth Sci. Rev. 161, 259-278.

Ramesh, P.T.-Woldeselassie, O. (2010): Development and Management of a Hilly Watershed in Hamelmalo Agricultural College Farm, as a Demonstration Site for Farmers and a Study Site for Students. Final Technical Report of the Project Financed by Eastern and Southern Africa Partnership Programme (ESAAP), Hamelmalo Agricultural College, Keren, p. 59.
Ramesh, P.T.-Isaac K.-Woldeselassie, O. (2015): Tillage and Irrigation Requirements of Sorghum (Sorghum bicolor L.) at Hamelmalo, Anseba Region of Eritrea.

Singh, S.-Boote, K.J.-Angadi, S.V.-Grover, K.K. (2017): Estimating water balance, evapotranspiration and water use efficiency of spring safflower using the CROPGRO model. Agric. Water Manag. 185, 137-144 of forests. Science 320, 1444-1449.

UNFCCC (Eritrea, Department of Environment) (2001): National Communication under the United Nations Framework Convention on Climate Change (UNFCCC). Asmara. 